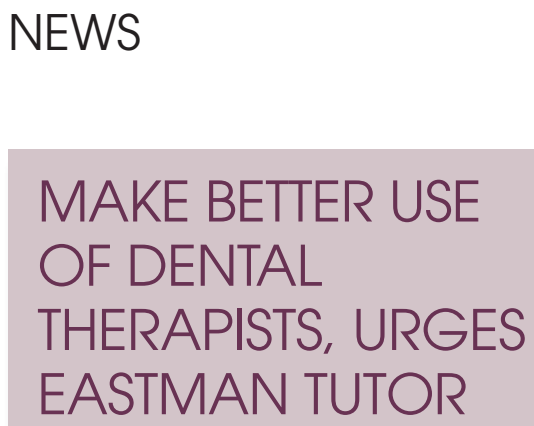

The skills and experience of dental therapists should be more widely recognised according to Debbie Hemington, DCP tutor at the Eastman Dental Institute.

'There is still a lot of ignorance about what therapists can do and they could be much better integrated into teams,' said Debbie, speaking at a reunion in September of graduates of New Cross, the UK's first school for dental therapists, which closed in 1983.

'There is still a tendency to look on us as "girls" who help dentists,' she said. 'But we have a wide range of skills and can now work in all services', she added. Debbie, now an examiner for dental therapists and hygienists for the Royal College of Surgeons of England, was the last student to graduate from New Cross. She is pictured (right) with Ruth Beckton, the first graduate, and dentist Ted Seal, the last director of New Cross.

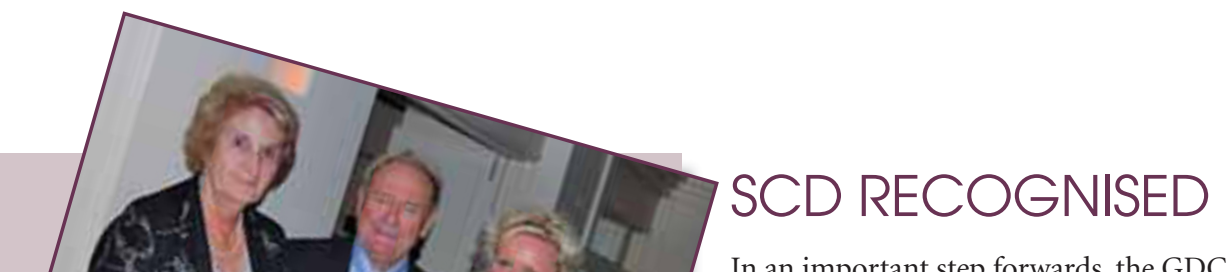

In an important step forwards, the GDC has recognised special care dentistry (SCD) as a specialty. The regulations which enable the opening of a new Specialist List in SCD were approved by the Council at its meeting in September. SCD is concerned with the improvement of oral health of individuals and groups in society who have a physical, sensory, intellectual, mental, medical, emotional or social impairment or disability or, more often, a combination of these factors. DCPs are likely to find themselves increasingly involved in the care of such individuals. need to resurrect community dental teams as a safety net and the Government should realise that therapists are very cost effective, he said.

Dr Seal, who led an unsuccessful campaign to save New Cross in the face of opposition from the Government and BDA, said any future attempt to abolish dental therapists would be unsuccessful partly because so many institutions were now involved in their training.

See page 14 for an account of the recent reunion of New Cross dental therapists.

\section{PROFESSIONALS TO BE RECOGNISED}

The Dental Laboratories Association

(DLA) has announced that the 2009 Chairman's Dinner will feature the presentation of awards for dental technology professionals and those still in training. The presentation will include awards for Dental Technology Student of the Year and Dental Technology Educator of the Year, Sales Representative of the Year and Trade Company of the Year, Dental Technician of the Year and DLA Member of the Year, Companion of the DLA Award and Outstanding Contribution to Dental Technology.

Set to take place on 31 January 2009 at the National Space Centre in Leicester, the event will see incoming Chairman Jonathan Bill inaugurated.

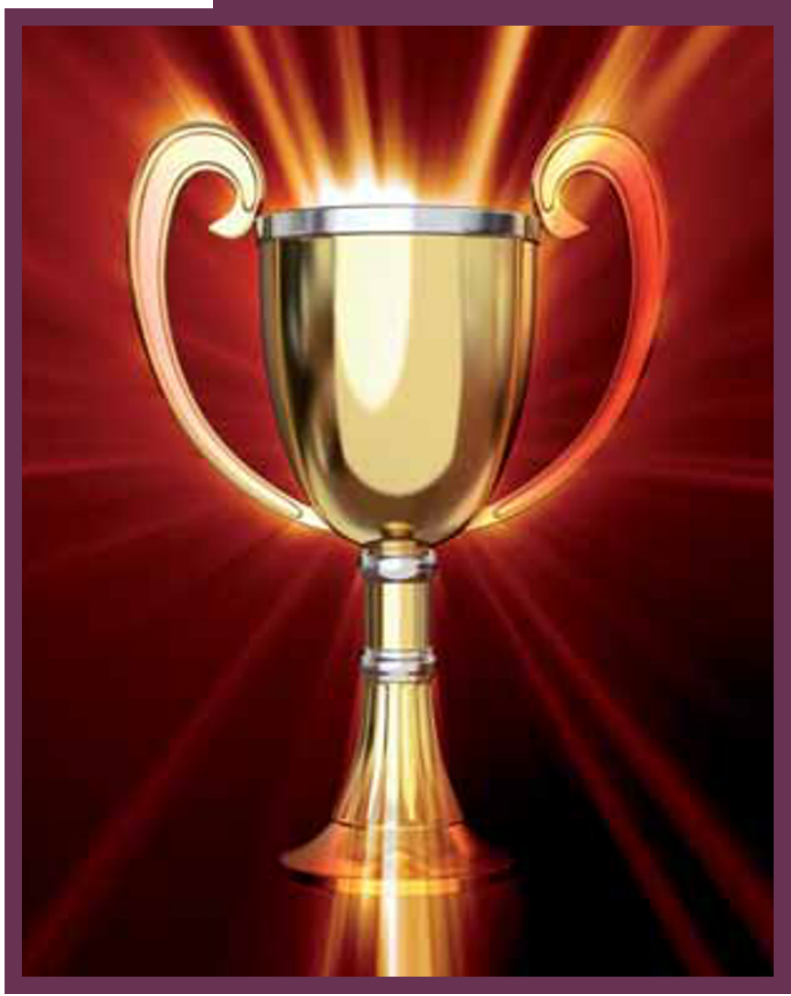

